\title{
Impact of Dietary Aromatic Amino Acids on Osteoclastic Activity
}

\author{
Mona El Refaey $\cdot$ Qing Zhong $\cdot$ Ke-Hong Ding $\cdot$ Xing-ming Shi $\cdot$ Jianrui Xu \\ Wendy B. Bollag • William D. Hill • Norman Chutkan • Richard Robbins • \\ Hugh Nadeau • Maribeth Johnson • Mark W. Hamrick • Carlos M. Isales
}

Received: 8 February 2014 / Accepted: 20 May 2014/Published online: 8 July 2014

(C) The Author(s) 2014. This article is published with open access at Springerlink.com

\begin{abstract}
We had shown that aromatic amino acid (phenylalanine, tyrosine, and tryptophan) supplementation prevented bone loss in an aging C57BL/6 mice model. In vivo results from the markers of bone breakdown suggested an inhibition of osteoclastic activity or differentiation. To assess osteoclastic differentiation, we examined the effects of aromatic amino acids on early /structural markers as vitronectin receptor, calcitonin receptor, and carbonic anhydrase II as well as, late/functional differentiation markers; cathepsin $\mathrm{K}$ and matrix metalloproteinase 9 (MMP-9). Our data demonstrate that the aromatic amino acids down-regulated early and late osteoclastic differentiation markers as measured by real time PCR. Our data also suggest a link between the vitronectin receptor and the secreted cathepsin $\mathrm{K}$ that both showed consistent effects to
\end{abstract}

The authors Mona El Refaey, Qing Zhong, Ke-Hong Ding, Xingming Shi, Jianrui Xu, Wendy B. Bollag, William D. Hill, Norman Chutkan, Richard Robbins, Hugh Nadeau, Maribeth Johnson, Mark W.

Hamrick, and Carlos M. Isales have no conflicts of interest to report.

M. E. Refaey · Q. Zhong · K.-H. Ding · X. Shi · J. Xu ·

W. B. Bollag · W. D. Hill · N. Chutkan · R. Robbins ·

H. Nadeau - M. W. Hamrick · C. M. Isales

Institute for Regenerative and Reparative Medicine, Medical

College of Georgia, Georgia Regents University, Augusta,

GA 30912, USA

Q. Zhong · K.-H. Ding · X. Shi · J. Xu · C. M. Isales

Departments of Medicine, Medical College of Georgia, Georgia

Regents University, Augusta, GA 30912, USA

X. Shi

Departments of Pathology, Medical College of Georgia, Georgia

Regents University, Augusta, GA 30912, USA

W. B. Bollag

Departments of Physiology, Medical College of Georgia,

Georgia Regents University, Augusta, GA 30912, USA the aromatic amino acid treatment. However, the nonattachment related proteins, calcitonin receptor, and carbonic anhydrase II, demonstrated less consistent effects in response to treatment. Our data are consistent with aromatic amino acids down-regulating osteoclastic differentiation by suppressing remodeling gene expression thus contributing initially to the net increase in bone mass seen in vivo.

Keywords Osteoclast - Amino acids - Cathepsin K · Carbonic anhydrase II $\cdot$ Calcitonin receptor

\section{Introduction}

Amino acids have been shown to exert direct effects on several tissues including the "amino acid-sensors" in pancreatic islets, pituitary, parathyroid gland, and liver and help regulate nutrient disposition [1]. In these tissues,

W. B. Bollag · W. D. Hill

Charlie Norwood VA Medical Center, Augusta, GA 30912, USA

W. D. Hill - N. Chutkan - M. W. Hamrick · C. M. Isales ( $\square)$

Department of Orthopaedic Surgery, Medical College of

Georgia, Georgia Regents University, Augusta, GA 30912, USA

e-mail: cisales@gru.edu

W. D. Hill · M. W. Hamrick · C. M. Isales

Departments of Cellular Biology and Anatomy, Medical College of Georgia, Georgia Regents University, Augusta, GA 30912, USA

M. Johnson

Departments of Biostatistics, Medical College of Georgia, Georgia Regents University, Augusta, GA 30912, USA 
Table 1 Primers used for real time PCR: list of primers of internal control, early and late osteoclast markers and their sequences

\begin{tabular}{|c|c|c|c|c|}
\hline Primer & Gene name & $\begin{array}{l}\text { Accession } \\
\text { number }\end{array}$ & Sequence $\left(5^{\prime} \rightarrow 3^{\prime}\right)$ & Size (bp) \\
\hline Vitronectin & Vitronectin (Vtn), & NM_011707 & $\begin{array}{l}\text { Fwd: TGCAGCGTTCGCCCTTCCTG } \\
\text { Rev: CCTCCTGGCTGGGTTGCTGC }\end{array}$ & 110 \\
\hline Cathepsin K & Cathepsin K(Ctsk) & NM_007802 & $\begin{array}{l}\text { Fwd: CGTGCAGCAGAACGGAGGCA } \\
\text { Rev: TAGCTGCCTTTGCCGTGGCG }\end{array}$ & 95 \\
\hline Calcitonin receptor & Calcitonin receptor (Calcr), & NM_007588 & $\begin{array}{l}\text { Fwd: ACATGATCCAGTTCACCAGGCAGA } \\
\text { Rev: AGGTTCTTGGTGACCTCCCAACTT }\end{array}$ & 107 \\
\hline MMP9 & $\begin{array}{l}\text { Matrix metallo-proteinase } \\
9 \text { (MMP9) }\end{array}$ & NM_013599 & $\begin{array}{l}\text { Fwd: TGAACAAGGTGGACCATGAGGTGA } \\
\text { Rev: TAGAGACTTGCACTGCACGGTTGA }\end{array}$ & 121 \\
\hline $\begin{array}{l}\text { Carbonic } \\
\text { anhydrase II }\end{array}$ & Carbonic anhydrase II & M81022 & $\begin{array}{l}\text { Fwd: ACCACTCCGCCTCTGCTGGA } \\
\text { Rev: ACGCCAGTTGTCCACCATCGC }\end{array}$ & 144 \\
\hline $18 \mathrm{~S}$ & $18 \mathrm{~S}$ ribosomal RNA (Rn18 s) & NR_003278 & $\begin{array}{l}\text { Fwd: AGTGCGGGTCATAAGCTTGC } \\
\text { Rev: GGGCCTCACTAAACCATCCA }\end{array}$ & 134 \\
\hline
\end{tabular}

amino acids have been shown to bind the extracellular calcium receptor (CaSR). The CaSR was first reported by House et al. [2] to be present in both human and mouse bone marrow cells. Bone breakdown is determined by osteoclastic activity. However, the direct effect of amino acids on osteoclasts is not known. In order to evaluate the effects of amino acids on osteoclastic development, we focused on expression of several common osteoclastic genes expressed at various levels during differentiation.

The vitronectin receptor is essential in bone remodeling as it binds to extracellular matrix proteins like osteopontin at the tri-peptide arginine-glycine-aspartic acid (RGD) recognition site and it is crucial for osteoclast polarization into clear zones and ruffled borders; two characteristic features of osteoclasts [3]. The calcitonin receptor is expressed on osteoclasts but not osteoblasts and a specific marker for osteoclast differentiation [4]. The calcitonin receptor (CTR) is a $\mathrm{G}$ protein-coupled receptor that is expressed at high levels by osteoclast, renal, and neural cells. It binds with highest affinity to calcitonin, which is a 32 amino acid peptide secreted by C-cells of the thyroid gland in response to elevated serum calcium levels. The main recognized action of calcitonin is to inhibit bone resorption [5].

Carbonic anhydrase II is an early marker of osteoclast differentiation and is important in bone resorption as it facilitates proton production and thus the acidic environment of the resorption lacunae. Previous work on carbonic anhydrase showed that mutation of the carbonic anhydrase II gene results in inhibition of bone resorption and osteopetrosis [6]. Studies in rat bone marrow cultures using acetazolamide, a specific carbonic anhydrase inhibitor, demonstrated that carbonic anhydrase II is crucial in proton generation in mature osteoclasts by showing a decrease in the 1,25 $(\mathrm{OH}) 2 \mathrm{D} 3$-induced formation of multinucleated tartrate-resistant acid phosphatase (TRAP)-positive cells, in a dose-dependent manner [7].
Matrix metalloproteinase 9 (MMP-9) is also a crucial marker in bone remodeling as a recent study identified that high levels of MMP-9 have been detected in osteoclasts, MMP-9 is considered unique because of its the strong abundance and selectivity of its expression in osteoclastic cells $[8,9]$. A previous study showed that MMP-9 knockout mice displayed a bone-developmental defect, suggesting an important role for this metalloproteinase in bone turnover and remodeling [10].

Cathepsin $\mathrm{K}$ is considered the major cysteine protease expressed in osteoclasts [11] and has a critical role in osteoclastic bone resorption. Cathepsin $\mathrm{K}$ can degrade telopeptide and triple helical regions of type I collagen [12] as well as osteonectin [13]. Cathepsin K knockout mice develop osteopetrosis as a result of a deficiency in matrix degradation and decreased bone resorption [14].

We focused on aromatic amino acids (phenylalanine, tyrosine, and tryptophan) in this study as previous lab findings showed that they increased cellular activity in bone [15]. We were interested in the effect of these aromatic amino acids on osteoclastic activity through evaluation of their effects on a number of breakdown genes as vitronectin receptor, calcitonin receptor, carbonic anhydrase II, MMP-9, and cathepsin K.

\section{Materials and Methods}

\section{Generation of Osteoclasts from Bone Marrow Macrophages}

Male C57BL/6 mice were purchased from Harlan Laboratories (Indianapolis, In, USA). Hematopoietic stem cells were isolated from 3-month-old male C57BL/6 mice to generate macrophages and induce osteoclasts at the Georgia Regents University Stem Cell Core Facility. In brief, six 
mice were euthanized by $\mathrm{CO}_{2}$ overdose followed by thoracotomy. Whole bone marrow aspirates were flushed from femora and tibiae, both ends of the bone were cut off and long bones were flushed to flush out all bone marrow from a protocol modified from Tropel et al. [16]. Bone marrow aspirates were centrifuged at $1300 \mathrm{rpm}$ for $5 \mathrm{~min}$ at room temperature and then cells were expanded in Alpha Modification of Eagle's Medium ( $\alpha$-MEM) (cat\#10-022) ( $\alpha-$ MEM; Cellgro, Mediatech, Manassas, VA, USA) supplemented with $10 \%$ heat-inactivated fetal bovine serum (cat\#S11150) (FBS; Atlanta Biologicals, Lawrenceville, GA, USA) and $1 \%$ penicillin-streptomycin (cat\#SV30010) (Hyclone Laboratories, Inc.) for $24 \mathrm{~h}$. A plastic pipette was used to collect the non-adherent cells; spun at $1300 \mathrm{rpm}$ for
$5 \mathrm{~min}$ and cells were expanded in $\alpha$-MEM and macrophagecolony stimulating factor (M-CSF) (cat\#315-02) (M-CSF, Peprotech Inc.) in a concentration of $50 \eta \mathrm{g} / \mathrm{ml}$ for 2 days to induce macrophages. After 2 days, bone marrow macrophages were attached to the bottom of the plate; cells were collected and spun at $1300 \mathrm{rpm}$ for $8 \mathrm{~min}$ at room temperature. 660,000 cells were seeded in each well of the six-well plate with M-CSF (cat\#315-02) (M-CSF, Peprotech Inc.) (20 ng/ml) and Rank-Ligand (cat\#315-11) (RANKL, Peprotech Inc.) $(100 \mathrm{ng} / \mathrm{ml})$. Different aromatic amino acid combinations were used to treat the cells during osteoclastic differentiation. After 6 days, osteoclasts were checked and confirmed with TRAP staining kit (Acid Phosphatase, Leukocyte (TRAP Kit; cat \# 387, Sigma-Aldrich Co.) a

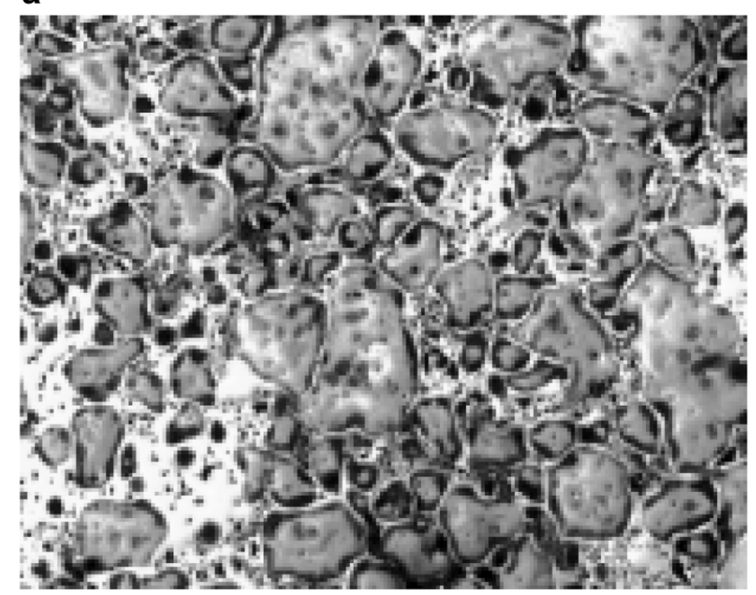

\section{c}

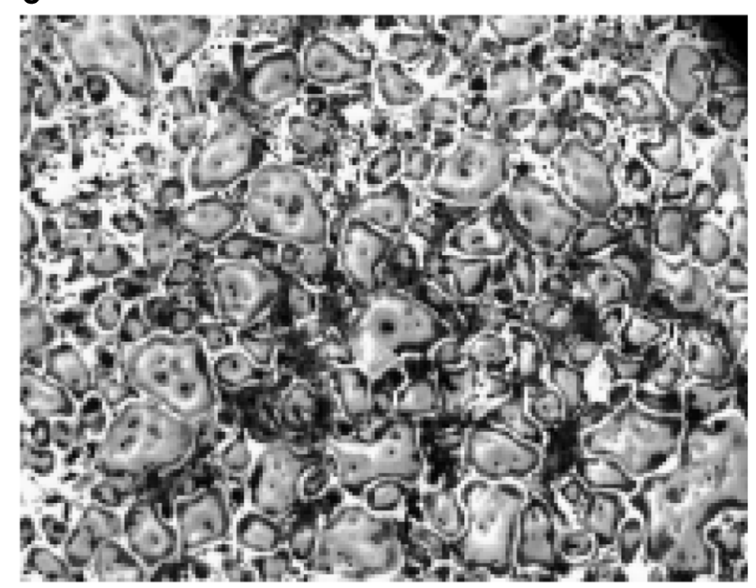

Fig. 1 TRAP staining of bone marrow macrophages. Bone marrow macrophages were collected and spun at $1300 \mathrm{rpm}$ for $8 \mathrm{~min}$ at room temperature, 660,000 cells were seeded in each well of the six-well plate with M-CSF $(20 \mathrm{ng} / \mathrm{ml})$ and RANKL (100 ng/ml). Shown is a representative picture of TRAP staining repeated at least three different times, a TRAP staining after 6 days of differentiation; b TRAP staining of osteoclasts incubated for the last 3 days with b

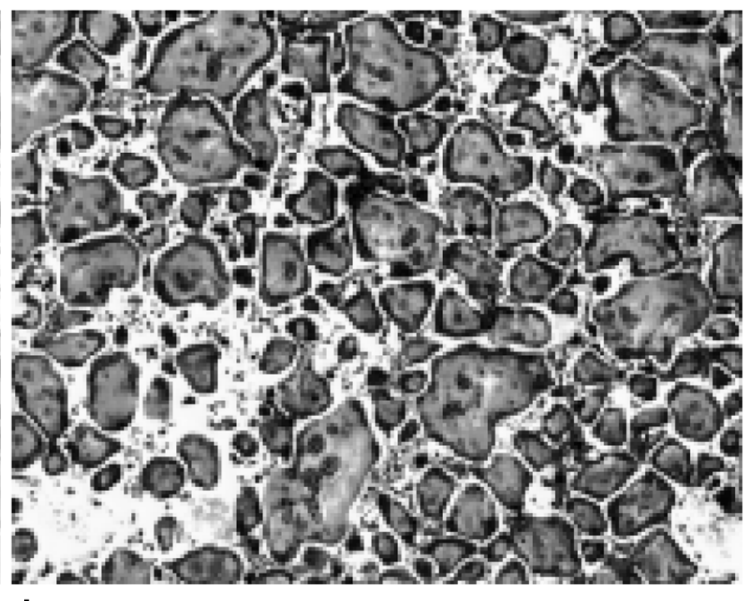

d

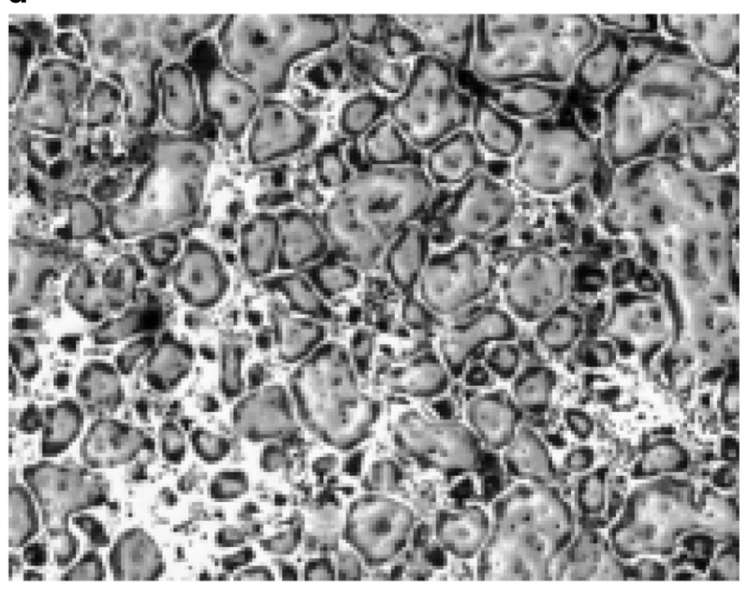

$100 \mu \mathrm{M}$ tryptophan. $\mathbf{c}$ TRAP staining of osteoclasts incubated for the last 3 days with $100 \mu \mathrm{M}$ phenylalanine. d TRAP staining of osteoclasts incubated for the last 3 days with $100 \mu \mathrm{M}$ Tyrosine. Photomicrographs showed multinucleated osteoclastic cells in the control and the treated groups and of note; no changes were detected in the morphology of the cells 
a
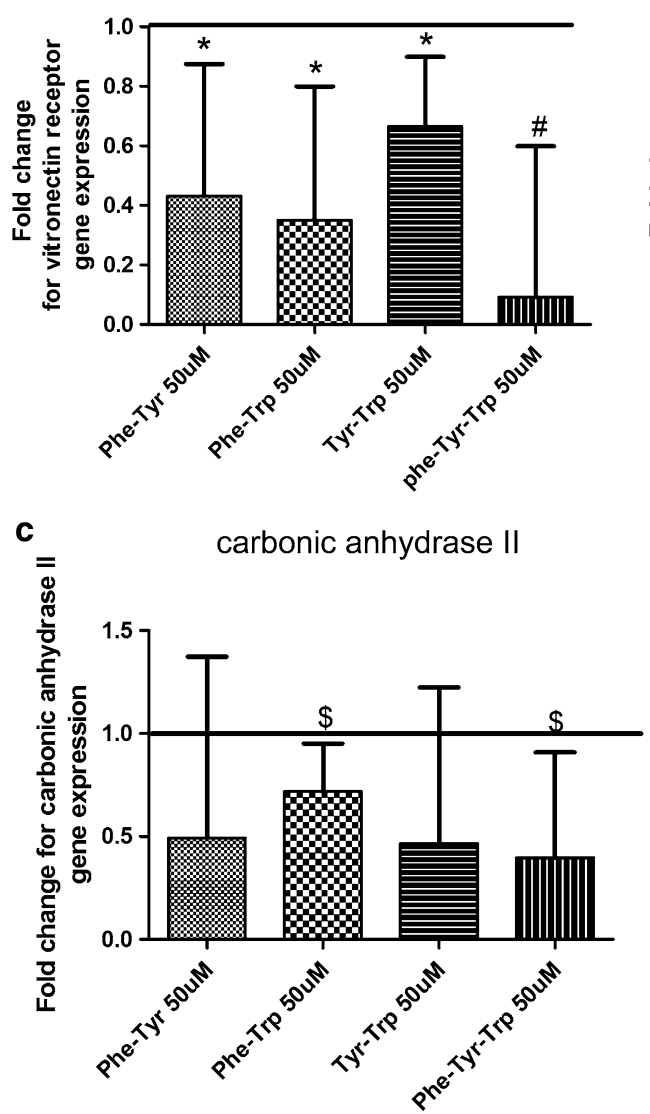

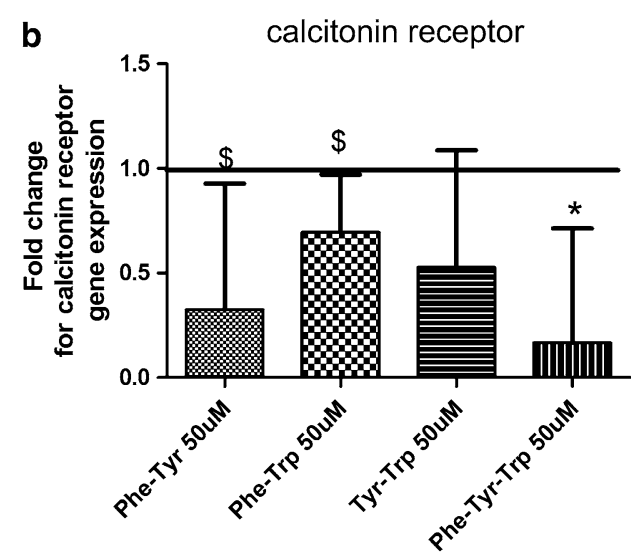

Fig. 2 Effects of different aromatic amino acid combinations on vitronectin receptor, calcitonin receptor, and carbonic anhydrase II gene expression. Bone marrow macrophages were collected and spun at $1300 \mathrm{rpm}$ for $8 \mathrm{~min}$ at room temperature, 660,000 cells were seeded in each well of the six-well plate with M-CSF $(10 \mathrm{ng} / \mathrm{ml})$ and RANKL (50 ng/ml). Different aromatic amino acid combinations were used to treat the cells during osteoclastic differentiation at a $50 \mu \mathrm{M}$ concentration. Untreated cells were used as a control. a Amino

\section{RNA Extraction and Quantitative PCR}

Total cellular RNA were isolated from cells with and without aromatic amino acid treatment using TRIZOL reagent (cat\#15596018) (Invitrogen) as previously described [17]. Equal amounts of total RNA $(2 \mu \mathrm{g})$ were reverse transcribed using SuperScript III First-Strand Synthesis System (cat\#18080-051) (Invitrogen) with Oligo(dT)20 as primer and $10 \mathrm{mMdNTP}$ mix in a $20-\mu \mathrm{l}$ reaction volume for $10 \mathrm{~min}$ at $25^{\circ} \mathrm{C}$ followed by $50 \mathrm{~min}$ at $50{ }^{\circ} \mathrm{C}$. The specificity was confirmed by electrophoresis of PCR products. The DNA $(1 \mu \mathrm{l})$ was used as template for real-time RT-PCR analysis using SYBR Green Master Mix (Applied Biosystems) and a Chromo-4 real-time RT-PCR instrument (MJ Research) as previously described [17]. PCR reactions were performed in triplicate, and the levels of mRNA expression were calculated by the $\Delta \Delta \mathrm{Ct}$ method using $18 \mathrm{~S}$ as an internal control (18-19). Primers for early/structural osteoclast

acid combinations that down-regulated vitronectin receptor gene expression. b AA treatment groups that down-regulated calcitonin receptor gene expression. c AA combinations that down-regulated carbonic anhydrase II gene expression. Untreated cells were used as control (fold change of expression $=1$ ). Results are expressed as geometric mean and geometric SEM for at least three independent experiments. ${ }^{*} p \leq 0.05, \# p \leq 0.01$ and $\$<0.1$

differentiation were: vitronectin receptor, calcitonin receptor, and carbonic anhydrase II and for late/functional osteoclastic differentiation were: cathepsin K and MMP-9. Sequences for different primers for early and late differentiation markers are listed in Table 1.

\section{In Vitro Resorption Assay}

Bone marrow macrophages were cultured in 16 well $\mathrm{BD}$ BioCoat Osteologic slides [18-28] (BD Bioscences, San Jose, CA, USA) at a cell density of 100,000 cells/well inMEM medium with $10 \%$ FBS (Life Technologies, Grand Island, NY, USA), $20 \mathrm{ng} / \mathrm{ml} \mathrm{M-CSF}$ and $100 \mathrm{ng} / \mathrm{ml}$ of RANK-L and the medium changed every 3 days. Indicated amino acids were added during the last 3 days of incubation. For each of the amino acids indicated the concentration used to stimulate the osteoclasts was double what was present in the basal-MEM medium. Baseline AA 
Fig. 3 Effects of different aromatic amino acid combinations on vitronectin receptor, calcitonin receptor, and carbonic anhydrase II gene expression. Various aromatic amino acid combinations were used to treat the cells during osteoclastic differentiation at a $100 \mu \mathrm{M}$ concentration and untreated cells were used as a control. a Amino acid combinations that downregulated vitronectin receptor gene expression. b Different treatment groups that downregulated calcitonin receptor gene expression. c Different amino acids that downregulated carbonic anhydrase II gene expression. Untreated cells were used as control (fold change of expression $=1$ ). Results are expressed as geometric mean and geometric SEM for at least three independent experiments. ${ }^{*} p \leq 0.05, \# p \leq 0.01$, and $p<0.1$
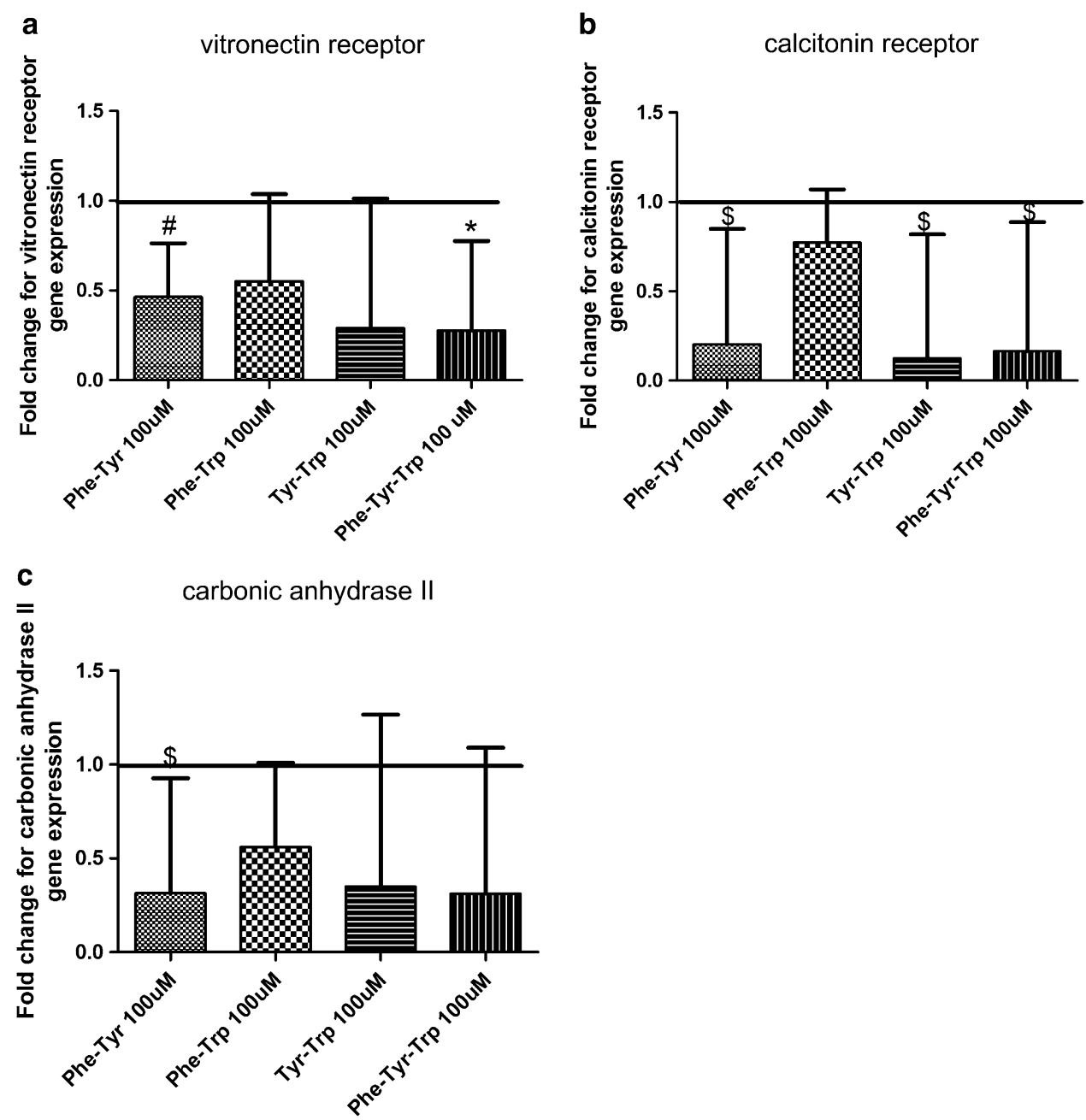

concentrations: (1) Phenylalanine-0.194 mM; (2) Tryptophan-0.049 mM; (3) Tyrosine- $0.231 \mathrm{mM}$; (4) Leucine$0.397 \mathrm{mM}$; (5) Isoleucine- $0.4 \mathrm{mM}$. Osteoclast identity was confirmed by TRAP staining. Resorption pits were visualized by Von Kossa staining. Pit area was estimated using NIH Image $\mathbf{J}$.

\section{Statistical Analysis}

Experiments were performed at least in triplicate from at least three independent experiments for cathepsin K, carbonic anhydrase II, vitronectin receptor, calcitonin receptor, and MMP9 expression. For real-time PCR data, the fold changes relative to control were computed using the comparative $\mathrm{C}_{\mathrm{T}}$ method $\left(\Delta \Delta \mathrm{C}_{\mathrm{T}}\right.$ Method) within experiment [29]. Data are expressed as the geometric mean fold change relative to control and geometric SEM. Since aromatic amino acid supplementation was hypothesized to reduce expression in these experiments, lower tail one-sample $\mathrm{t}$-tests using a lognormal distribution were performed. Statistical significance was determined at alpha $=0.05$ and trends were assessed between 0.05 and 0.10 . No multiple testing adjustments were made [30]. Data were analyzed using SAS@ 9.3 (SAS Institute, Inc., Cary, NC, USA).

\section{Results}

Effects of Aromatic Amino Acids on Early/Structural Osteoclast Markers

The effects of aromatic amino acid combinations on the early osteoclastic gene markers, vitronectin receptor, calcitonin receptor, and carbonic anhydrase II were first examined. Before extracting the RNA, osteoclast identity was confirmed by TRAP staining (Fig. 1). Aromatic amino acids $(50$ and $100 \mu \mathrm{M})$ down-regulated vitronectin gene expression in the TRAP stained cells. At the $50 \mu \mathrm{M}$ concentration, the AA combinations of phenylalalanine and tyrosine, phenylalanine and tryptophan, tyrosine and tryptophan and phenylalanine-tyrosine-tryptophan all significantly decreased the gene expression of vitronectin 

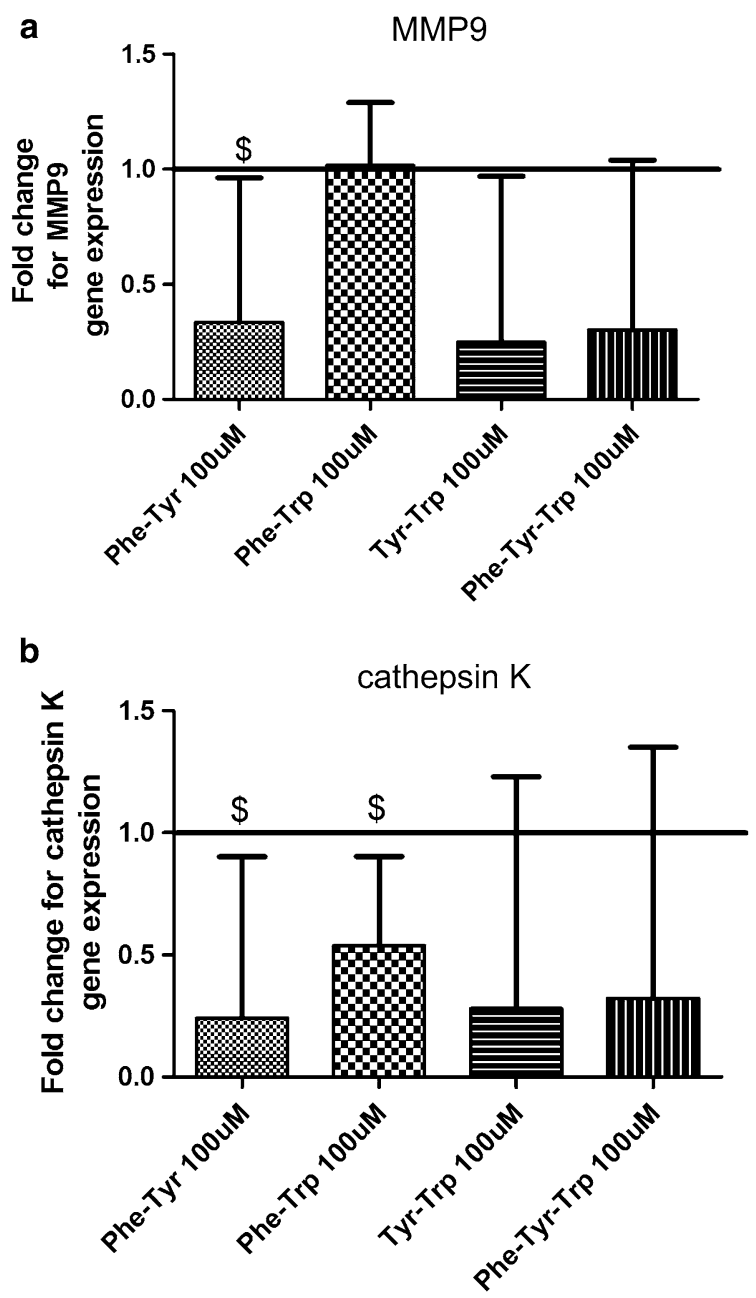

Fig. 4 Effects of different aromatic amino acids on matrix metalloproteinase 9, cathepsin $\mathrm{K}$ gene expression. Isolated bone marrow macrophages: a Amino acid combinations $(50 \mu \mathrm{M})$ down-regulated matrix metalloproteinase 9 gene expression. b AA treatment groups $(50 \mu \mathrm{M})$ that down-regulated cathepsin $\mathrm{K}$ gene expression. Untreated cells were used as a control (fold change of expression $=1$ ). Results are expressed as geometric mean and geometric SEM for at least three independent experiments. $\$<0.1$

receptor with a $p$ value $\leq 0.05$ as shown in Fig. 2a. At the $100 \mu \mathrm{M}$ concentration, the AA combinations of phenylalanine-tyrosine and phenylalanine-tyrosine-tryptophan similarly significantly decreased the expression of vitronectin receptor gene expression (Fig. 3a).

For the calcitonin receptor gene expression, the aromatic amino acids combination of phenylalanine-tyrosine, phenylalanine-tryptophan, and phenylalanine-tyrosine-tryptophan in a $50 \mu \mathrm{M}$ concentration down-regulated the gene expression as in Fig. 2b. A similar trend of gene expression down-regulation was observed at $100 \mu \mathrm{M}$ concentration in the following AA combinations; phenylalanine-tyrosine, tyrosine-tryptophan, and phenylalanine-tyrosine-tryptophan (Fig. 3b).
For carbonic anhydrase II, the AA combinations of phenylalanine-tryptophan and phenylalanine-tyrosinetryptophan $(50 \mu \mathrm{M})$ decreased its gene expression as shown in Fig. 2c. In contrast at $100 \mu \mathrm{M}$ only the phenylalanine-tyrosine combination showed a trend of downregulation (Fig. 3c).

\section{Effect of Aromatic Amino Acids on Late/Functional Markers of Osteoclasts}

At the AA concentration of $100 \mu \mathrm{M}$ the AA combinations of phenylalanine-tyrosine, tyrosine-tryptophan and phenylalanine-tyrosine-tryptophan all down-regulated MMP-9 expression although none of these changes reached statistical significance (Fig. 4a).

For cathepsin $\mathrm{K}(50 \mu \mathrm{M})$, the AA combinations of tyrosine-tryptophan and phenylalanine-tyrosine-tryptophan down-regulated its gene expression. At the higher AA concentration $(100 \mu \mathrm{M})$, the combinations of phenylalanine-tyrosine and phenylalanine-tryptophan down-regulated cathepsin $\mathrm{K}$ gene expression (Fig. 4b).

\section{Effect of Aromatic Amino Acids on Osteoclastic Activity}

To evaluate the impact of aromatic amino acids on osteoclastic activity, we used the pit resorption assay (Fig. 5). Isolated bone marrow macrophages were differentiated into osteoclasts in the presence of M-CSF and RANK-L and exposed to aromatic amino acids (tyrosine, tryptophan, or phenylalanine) or leucine or isoleucine. All the aromatic amino acids significantly increased resorption activity. Non aromatic amino acids leucine and isoleucine also increased resorptive activity but to a lesser extent.

\section{Discussion}

In present study, we examined the effects of aromatic amino acids on osteoclast differentiation as our previous data showed that aromatic amino acid supplementation prevented bone loss in aging C57BL/6 mice placed on a low protein diet [15]. Other studies [31, 32] by Hampson et al. [31] showed that nutritional supplementation (12-24 g protein, 12-24 g fat, and 37-74 g carbohydrate together with vitamins, minerals, and trace elements daily) in elderly women over a 1 year interval showed a reduction in serum osteoprotegerin and serum C-terminal telopeptide of type I collagen by $\sim 30 \%$ and showed an increase in bone alkaline phosphatase and osteocalcin and glucose has been reported to affect osteoclastic activity as Wittrant et al. [33] showed the first evidence that high D-glucose inhibited RANKL-mediated signaling events that 
a

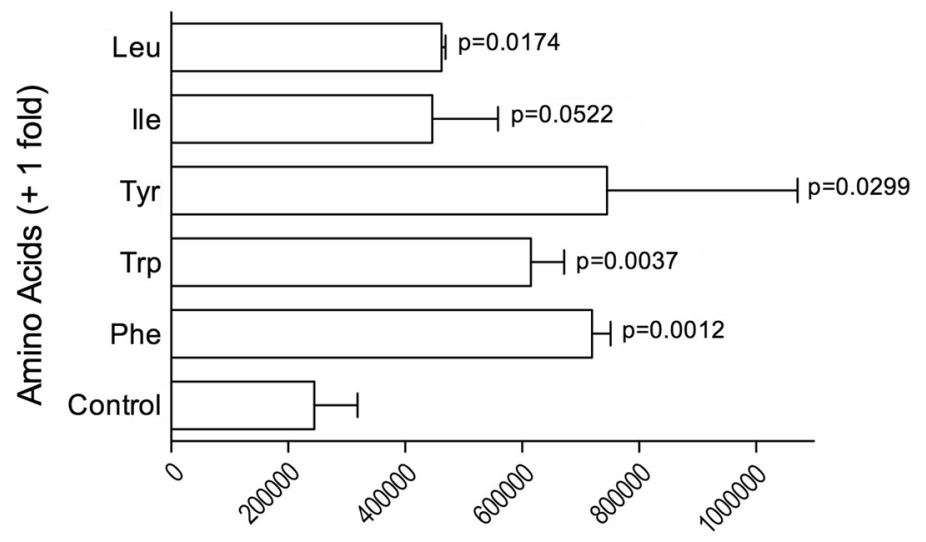

b

\section{Pit Area $\left(\mu \mathrm{m}^{2}\right)$}

Trp

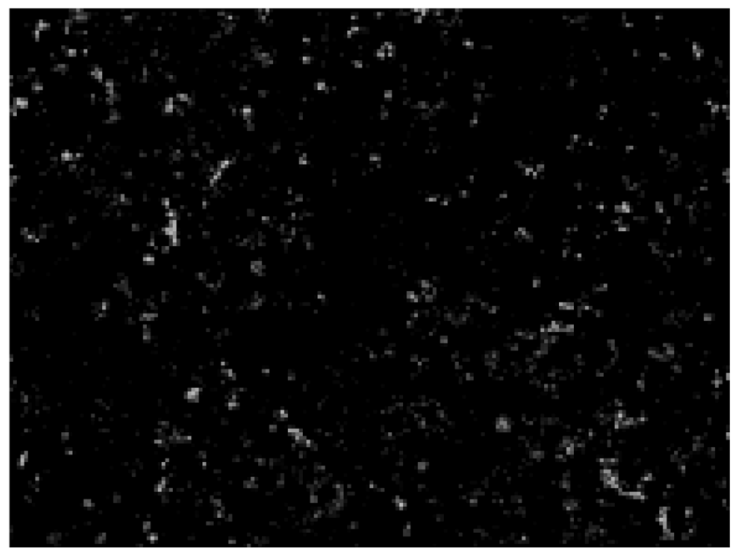

Phe

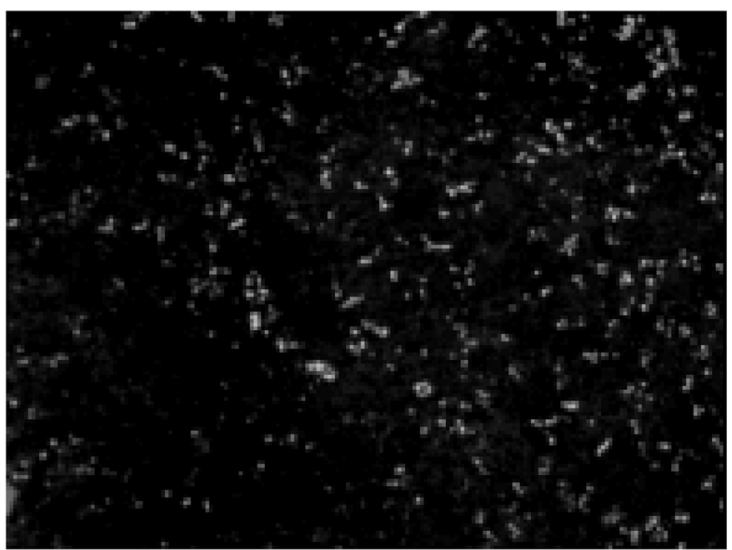

Fig. 5 Effects of different amino acids on osteoclastic resorption activity. a Bone marrow macrophages were cultured in 16 well BD BioCoat Osteologic slides and stimulated with the indicated amino acid for 3 days. Resorption pits were visualized by Von Kossa staining. Pit area was estimated using NIH Image J. Results are

correlated to osteoclast differentiation and function. However, the effect of aromatic amino acids on osteoclasts had not previously been examined. The C57BL/6 mouse model was used due to consistent results from these mice with

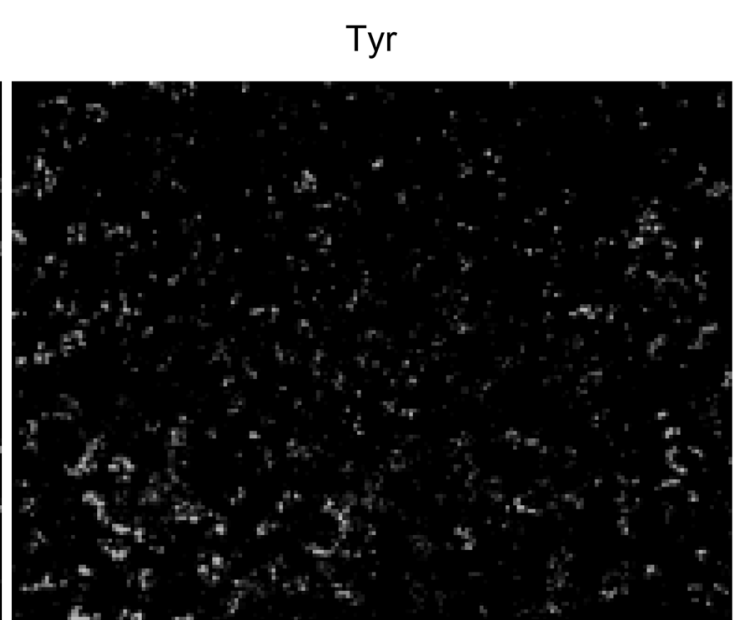

Con

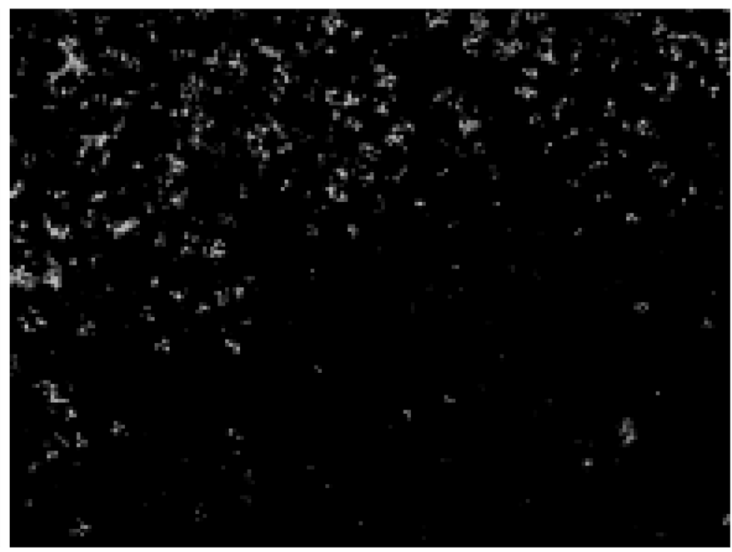

expressed as mean \pm SEM for at least three independent experiments. Significance value is listed above each graph bar. b Aromatic amino acids (Phe, Tyr and Trp) showed more resorption pits compared to the control

published data from human clinical trials and because it is a model of aging as previously characterized by our group [34]. Aromatic amino acids down-regulated vitronectin gene expression and alternatively osteoclast differentiation 
and polarization as vitronectin gene is crucial for osteoclast polarization into clear zones and ruffled borders; two of the most characteristic features of osteoclasts [3]. Our results also demonstrated that aromatic amino acids down-regulated early osteoclast differentiation by suppressing calcitonin receptor gene expression as the CTR is a G proteincoupled surface receptor that is expressed at high levels by osteoclast and binds with highest affinity to calcitonin that regulates calcium homeostasis [5]. Real time PCR data showed a decrease in carbonic anhydrase II gene expression, an early marker of osteoclast differentiation and important for bone resorption as it facilitates proton production and thus the acidic environment of the resorption lacunae [7].

MMP-9 and cathepsin K are considered late markers of osteoclastic differentiation as studies showed that NFATc1 plays a key role in up-regulating expression of genes required for osteoclast maturation, such as TRAP [35], cathepsin K[36], or MMP-9[37], which are crucial for bone resorption mediated by mature osteoclasts. Our data demonstrate a down-regulation in MMP-9 and cathepsin K as MMP-9 is crucial in bone turnover and remodeling [10] and cathepsin $\mathrm{K}$ is a major cysteine protease expressed in osteoclasts [11] and has a critical role in osteoclastic bone resorption. However, our TRAP staining photomicrographs showed no changes in the morphology or the number of nuclei of the cells in response to the aromatic amino acid treatment and these are consistent with PCR data that showed most effects on the attachment proteins.

Unexpectedly aromatic amino acids increased in vitro resorptive activity (Fig. 5). These data would suggest that aromatic amino acids main suppressive effect on osteoclasts may be through modulation of their attachment since resorptive activity was actually increased in the mature osteoclasts.

In conclusion, our data demonstrate that aromatic amino acids downregulate early and late osteoclast differentiation markers thus may contribute through this mechanism to the net increase in bone mass seen in vivo. Our data also suggest a link between the attachment protein; vitronectin receptor and the secreted cathepsin $\mathrm{K}$ that both showed consistent effects to the amino acid treatment. However, the non-attachment related proteins, carbonic anhydrase II, demonstrated less consistent effects in response to treatment.

Acknowledgments Funding for this research was provided by the National Institute on Aging (P01 AG036675).

Human and Animal Rights and Informed Consent All experiments were approved by the Institutional Animal Care and Use Committee at Georgia Regents University (Protocol \#: BR09-11-265; Augusta, GA). The mice were housed in AAALAC accredited facilities under the supervision of a veterinarian. Georgia Regents
University complies with the NIH policy on animal welfare, the Animal Welfare Act, and all other applicable federal, state and local laws. All available measures were taken to minimize pain and suffering.

Open Access This article is distributed under the terms of the Creative Commons Attribution License which permits any use, distribution, and reproduction in any medium, provided the original author(s) and the source are credited.

\section{References}

1. Rasschaert J, Malaisse WJ (1999) Expression of the calciumsensing receptor in pancreatic islet B-cells. Biochem Biophys Res Commun 264:615-618

2. House MG, Kohlmeier L, Chattopadhyay N, Kifor O, Yamaguchi T et al (1997) Expression of an extracellular calcium-sensing receptor in human and mouse bone marrow cells. J Bone Miner Res 12:1959-1970

3. Hill PA (1998) Bone remodelling. Br J Orthod 25:101-107

4. Dacquin R, Davey RA, Laplace C, Levasseur R, Morris HA et al (2004) Amylin inhibits bone resorption while the calcitonin receptor controls bone formation in vivo. J Cell Biol 164:509-514

5. Turner AG, Tjahyono F, Chiu WS, Skinner J, Sawyer R et al (2011) The role of the calcitonin receptor in protecting against induced hypercalcemia is mediated via its actions in osteoclasts to inhibit bone resorption. Bone 48:354-361

6. Felix R, Hofstetter W, Cecchini MG (1996) Recent developments in the understanding of the pathophysiology of osteopetrosis. Eur J Endocrinol 134:143-156

7. Lehenkari P, Hentunen TA, Laitala-Leinonen T, Tuukkanen J, Vaananen HK (1998) Carbonic anhydrase II plays a major role in osteoclast differentiation and bone resorption by effecting the steady state intracellular $\mathrm{pH}$ and $\mathrm{Ca} 2+$. Exp Cell Res 242:128-137

8. Andersen TL, del Carmen Ovejero M, Kirkegaard T, Lenhard T, Foged NT et al (2004) A scrutiny of matrix metalloproteinases in osteoclasts: evidence for heterogeneity and for the presence of MMPs synthesized by other cells. Bone 35:1107-1119

9. Galliera E, Randelli P, Dogliotti G, Dozio E, Colombini A et al (2010) Matrix metalloproteases MMP-2 and MMP-9: are they early biomarkers of bone remodelling and healing after arthroscopic acromioplasty? Injury 41:1204-1207

10. Vu TH, Shipley JM, Bergers G, Berger JE, Helms JA et al (1998) MMP-9/gelatinase B is a key regulator of growth plate angiogenesis and apoptosis of hypertrophic chondrocytes. Cell 93:411-422

11. Drake FH, Dodds RA, James IE, Connor JR, Debouck C et al (1996) Cathepsin K, but not cathepsins B, L, or S, is abundantly expressed in human osteoclasts. J Biol Chem 271:12511-12516

12. Garnero P, Borel O, Byrjalsen I, Ferreras M, Drake FH et al (1998) The collagenolytic activity of cathepsin $\mathrm{K}$ is unique among mammalian proteinases. J Biol Chem 273:32347-32352

13. Bossard MJ, Tomaszek TA, Thompson SK, Amegadzie BY, Hanning CR et al (1996) Proteolytic activity of human osteoclast cathepsin K. Expression, purification, activation, and substrate identification. J Biol Chem 271:12517-12524

14. Gowen M, Lazner F, Dodds R, Kapadia R, Feild J et al (1999) Cathepsin $\mathrm{K}$ knockout mice develop osteopetrosis due to a deficit in matrix degradation but not demineralization. J Bone Miner Res 14:1654-1663

15. Ding KH ZQ, Wyatt B, Rowse J, Shi XM, Xu J, El Refaey M, Hill W, Bollag W, Elsalanty M, Howie N, Insogna K, Chutkan N, Hunter M, Hamrick M, Isales C (2013) Selective amino acid supplementation can exacerbate or prevent low protein-induced 
bone loss in the aged animal. American Bone and Mineral Society Annual Meeting MO0004.

16. Tropel P, Noel D, Platet N, Legrand P, Benabid AL et al (2004) Isolation and characterisation of mesenchymal stem cells from adult mouse bone marrow. Exp Cell Res 295:395-406

17. Shi X, Shi W, Li Q, Song B, Wan M et al (2003) A glucocorticoid-induced leucine-zipper protein, GILZ, inhibits adipogenesis of mesenchymal cells. EMBO Rep 4:374-380

18. Hwang SY, Putney JW (2012) Orai1-mediated calcium entry plays a critical role in osteoclast differentiation and function by regulating activation of the transcription factor NFATc1. FASEB J 26:1484-1492

19. Otero JE, Dai S, Foglia D, Alhawagri M, Vacher J et al (2008) Defective osteoclastogenesis by IKKbeta-null precursors is a result of receptor activator of NF-kappaB ligand (RANKL)induced JNK-dependent apoptosis and impaired differentiation. J Biol Chem 283:24546-24553

20. Yang M, Kream BE (2008) Calcitonin induces expression of the inducible cAMP early repressor in osteoclasts. Endocrine 33: 245-253

21. Lin RW, Chen CH, Wang YH, Ho ML, Hung SH et al (2009) (-)Epigallocatechin gallate inhibition of osteoclastic differentiation via NF-kappaB. Biochem Biophys Res Commun 379:1033-1037

22. Choi SW, Park KI, Yeon JT, Ryu BJ, Kim KJ et al (2014) Antiosteoclastogenic activity of matairesinol via suppression of $\mathrm{p} 38 /$ ERK-NFATc1 signaling axis. BMC Complement Altern Med $14: 35$

23. Revu S, Neregard P, af Klint E, Korotkova M, Catrina AI (2013) Synovial membrane immunohistology in early-untreated rheumatoid arthritis reveals high expression of catabolic bone markers that is modulated by methotrexate. Arthritis Res Ther 15:R205

24. Soares-Schanoski A, Gomez-Pina V, del Fresno C, RodriguezRojas A, Garcia F et al (2007) 6-Methylprednisolone down-regulates IRAK-M in human and murine osteoclasts and boosts bone-resorbing activity: a putative mechanism for corticoidinduced osteoporosis. J Leukoc Biol 82:700-709

25. Nair RR, Avila H, Ma X, Wang Z, Lennartz M et al (2008) A novel high-throughput screening system identifies a small molecule repressive for matrix metalloproteinase- 9 expression. Mol Pharmacol 73:919-929

26. Bharti AC, Takada Y, Aggarwal BB (2004) Curcumin (diferuloylmethane) inhibits receptor activator of NF-kappa B ligand- induced NF-kappa B activation in osteoclast precursors and suppresses osteoclastogenesis. J Immunol 172:5940-5947

27. Lecourt S, Mouly E, Freida D, Cras A, Ceccaldi R et al (2013) A prospective study of bone marrow hematopoietic and mesenchymal stem cells in type 1 Gaucher disease patients. PLoS One 8:e69293

28. Mocsai A, Humphrey MB, Van Ziffle JA, Hu Y, Burghardt A et al (2004) The immunomodulatory adapter proteins DAP12 and $\mathrm{Fc}$ receptor gamma-chain (FcRgamma) regulate development of functional osteoclasts through the Syk tyrosine kinase. Proc Natl Acad Sci U S A 101:6158-6163

29. Livak KJ, Schmittgen TD (2001) Analysis of relative gene expression data using real-time quantitative PCR and the 2(-Delta Delta C(T)) Method. Methods 25:402-408

30. Rothman KJ (1990) No adjustments are needed for multiple comparisons. Epidemiology 1:43-46

31. Hampson G, Martin FC, Moffat K, Vaja S, Sankaralingam S et al (2003) Effects of dietary improvement on bone metabolism in elderly underweight women with osteoporosis: a randomised controlled trial. Osteoporos Int 14:750-756

32. Reid IR, Cornish J, Baldock PA (2006) Nutrition-related peptides and bone homeostasis. J Bone Miner Res 21:495-500

33. Wittrant Y, Gorin Y, Woodruff K, Horn D, Abboud HE et al (2008) High d(+)glucose concentration inhibits RANKL-induced osteoclastogenesis. Bone 42:1122-1130

34. Hamrick MW, Ding KH, Pennington C, Chao YJ, Wu YD et al (2006) Age-related loss of muscle mass and bone strength in mice is associated with a decline in physical activity and serum leptin. Bone 39:845-853

35. Takayanagi H, Kim S, Koga T, Nishina H, Isshiki M et al (2002) Induction and activation of the transcription factor NFATc1 (NFAT2) integrate RANKL signaling in terminal differentiation of osteoclasts. Dev Cell 3:889-901

36. Matsumoto M, Kogawa M, Wada S, Takayanagi H, Tsujimoto M et al (2004) Essential role of p38 mitogen-activated protein kinase in cathepsin $\mathrm{K}$ gene expression during osteoclastogenesis through association of NFATc1 and PU.1. J Biol Chem 279:45969-45979

37. Sundaram K, Nishimura R, Senn J, Youssef RF, London SD et al (2007) RANK ligand signaling modulates the matrix metalloproteinase-9 gene expression during osteoclast differentiation. Exp Cell Res 313:168-178 